
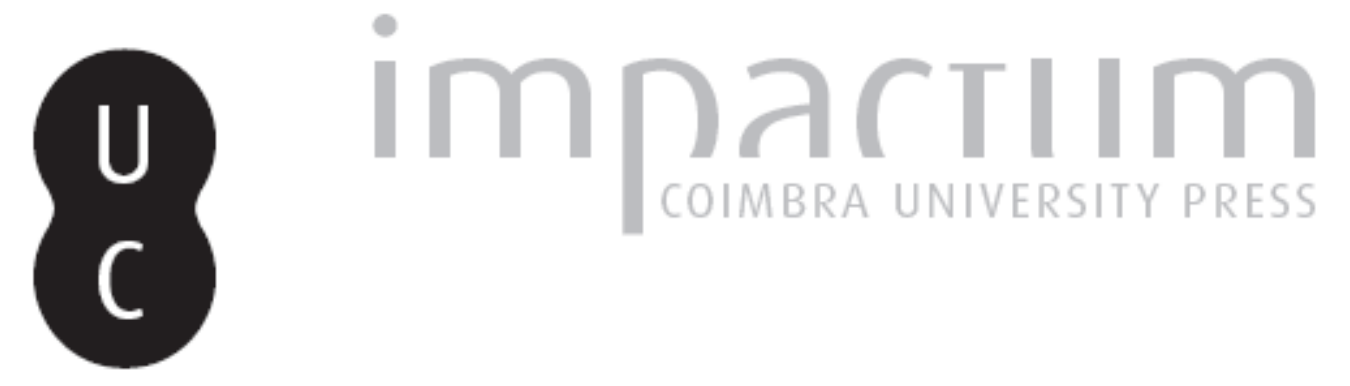

Observações sobre a importância das regras de origem no comércio internacional

Autor(es): $\quad$ Cunha, Luís Pedro

Publicado por: Faculdade de Direito da Universidade de Coimbra

URL persistente:

URI:http://hdl.handle.net/10316.2/30705

DOI:

DOI:http://dx.doi.org/10.14195/0870-4260_55_5

Accessed : $\quad$ 26-Apr-2023 13:07:50

A navegação consulta e descarregamento dos títulos inseridos nas Bibliotecas Digitais UC Digitalis, UC Pombalina e UC Impactum, pressupõem a aceitação plena e sem reservas dos Termos e Condições de Uso destas Bibliotecas Digitais, disponíveis em https://digitalis.uc.pt/pt-pt/termos.

Conforme exposto nos referidos Termos e Condições de Uso, o descarregamento de títulos de acesso restrito requer uma licença válida de autorização devendo o utilizador aceder ao(s) documento(s) a partir de um endereço de IP da instituição detentora da supramencionada licença.

Ao utilizador é apenas permitido o descarregamento para uso pessoal, pelo que o emprego do(s) título(s) descarregado(s) para outro fim, designadamente comercial, carece de autorização do respetivo autor ou editor da obra.

Na medida em que todas as obras da UC Digitalis se encontram protegidas pelo Código do Direito de Autor e Direitos Conexos e demais legislação aplicável, toda a cópia, parcial ou total, deste documento, nos casos em que é legalmente admitida, deverá conter ou fazer-se acompanhar por este aviso. 
VOLUME LV

$\begin{array}{llll}2 & 0 & 1 & 2\end{array}$

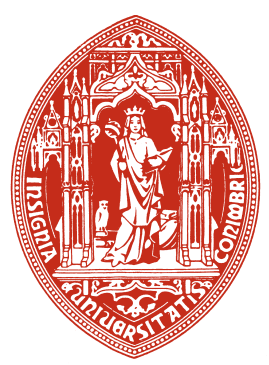




\section{OBSERVAÇÕES SOBRE A IMPORTÂNCIA DAS REGRAS DE ORIGEM NO COMÉRCIO INTERNACIONAL}

1. A aferição da origem de um produto não levanta dificuldades quando o processo de produção desse bem se integra, na totalidade, numa única economia. Em outros casos, no entanto, a imputação da origem a uma determinada economia suscita melindre. Em primeiro lugar, quando existe fragmentação do processo produtivo por várias economias. Nestas circunstâncias, não é certa a origem do bem. Este primeiro caso está largamente associado ao investimento directo externo (IDE) e à actuação de multinacionais. Em segundo lugar - e o melindre que referimos acentuar-se-á -, quando se introduzem ou multiplicam os casos de tratamento pautal preferencial, ou seja, de discriminação comercial, por via da celebração de acordos de integração regional (AIR) ou da concessão de preferências alfandegárias verticais (de países ou espaços de integração regional (EIR) desenvolvidos a beneficiários em vias de desenvolvimento $)^{1}$.

Em casos destes aplicam-se regras de origem. Estas podem definir-se como o conjunto de requisitos que o processo produtivo de um bem final deve cumprir, especialmente no que

1 Neste sentido, entre muitos outros, Lloyd, 2002: 174. O autor refere exemplos de legislação comercial dos EUA, do Canadá ou da Austrália com este tipo de regras já antes da 2. ${ }^{a}$ Guerra Mundial. 
toca à utilização de inputs ou de bens intermediários, para que a sua "nacionalidade" seja imputada ao país de exportação. As regras de origem, muito importantes nos domínios das preferências alfandegárias e das zonas de comércio livre (ZCL), são também relevantes de um ponto de vista estatístico, técnico-produtivo, económico, e ainda em várias outras áreas do comércio internacional (na verdade, em todas aquelas em que a discriminação impõe a aferição da origem).

Registe-se que, tradicionalmente (e hodiernamente), estas regras imputam a origem a apenas uma economia. A origem é tratada como um conceito de tudo ou nada ${ }^{2}$. Por outro lado, a noção de origem deve distinguir-se da noção de proveniência. Esta prende-se com o país onde se iniciou o último transporte da mercadoria para o país de importação e tem relevância sobretudo para a aplicação de medidas sanitárias ou fitosanitárias.

2. As regras de origem podem ser preferenciais ou não preferenciais. As primeiras relacionam-se com o facto de a importação de uma mercadoria poder estar sujeita a taxas de tributação alfandegária diversas, ou não estar de todo sujeita a encargos alfandegários, em função das relações, preferenciais ou não, estabelecidas entre a economia importadora e o país produtor/exportador; a questão da determinação da origem ganha então alguma acuidade, nomeadamente se mais de um país tiver participado no fabrico de uma dada mercadoria, sendo então necessário relacionar a origem da mercadoria com um dos países que intervieram no processo produtivo. Destas regras de origem, com importância acrescida pela intensificação das relações comerciais preferenciais, trataremos mais tarde e a diversos títulos. As regras de origem não

${ }^{2}$ Questionando esta prática e com propostas de regras de origem plurinacionais (multi-country), LlOYd, 2002: 176 ss. 
preferenciais atêm-se, nomeadamente, a casos de aplicação de medidas comerciais restritivas, com ou sem natureza retaliatória. Sublinharemos os casos das medidas de salvaguarda, mormente de restrições quantitativas, e de impostos antidumping ou compensadores. Aplicar-se-ão ainda em outros domínios do comércio internacional, por exemplo compras públicas ou etiquetagem de produtos.

3. A redução nas barreiras comerciais, a descida dos custos de transporte, a facilitação das comunicações internacionais e a proliferação dos AIR intensificou tanto o comércio preferencial como as trocas internacionais de bens intermediários. Não obstante, o quadro jurídico internacional que se aplica à construção e definição das regras de origem pode considerar-se frouxo. Deve, em primeiro lugar, nomear-se a Convenção Internacional para a Simplificação e Harmonização dos Regimes Aduaneiros, conhecida como convenção de Quioto, celebrada em 1973 e que entrou em vigor em 1974. Estabeleceu-se que a origem dos bens deveria ser afectada ao país no qual uma última "transformação substancial" tivesse sido realizada. Mas nem a Convenção assumiu natureza vinculativa nem, em particular, se impuseram métodos criteriosos para determinar exactamente qual o país de origem.

No que respeita à $\mathrm{OMC}$, nem no art. $24^{\circ}$ do GATT nem na cláusula de habilitação se estabelecem regras de origem. As regras de origem preferenciais são apenas objecto de uma Declaração Comum não vinculativa. Por seu turno, o acordo do Uruguay Round sobre regras de origem incide sobre regras não preferenciais. $\mathrm{O}$ acordo impõe alguma disciplina, no que respeita à transparência e à consistência na aplicação destas regras, e estabelece como objectivo a harmonização internacional das regras de origem, algo que ainda não se verificou. Nesta matéria, decorrem negociações sob os auspícios da OMC e da Organização Mundial das Alfândegas. 
4. As regras de origem preferenciais, aquelas que definem as condições de elegibilidade dos bens ao tratamento preferencial, podem ser classificadas em regras de regime e em regras de lista (com aspectos comuns às regras não preferenciais).

No âmbito das regras de lista, assume-se que o bem (exportado) foi inteiramente obtido na economia exportadora ou que aí foi suficientemente transformado (tendo em conta a importação de inputs do resto do mundo). Assim, em casos de internacionalização do processo produtivo, utiliza-se, genericamente, o critério da transformação suficiente (ou substancial) para a determinação da origem ${ }^{3}$. Este tipo de transformação pode averiguar-se de três formas: a) descrevendo-se - para cada produto - qual é a transformação ou operação de complemento de fabrico que confere a origem; $b$ ) adoptando-se o critério da mudança de posição pautal: qualquer transformação ou operação de complemento de fabrico de uma mercadoria que a leve a obter uma posição pautal diferente da posição pautal dos seus inputs chega, em princípio, para conferir a origem; c) aceitando-se o critério do conteúdo local: determina-se, em regra, a percentagem de valor acrescentado, em relação ao valor do produto, que se considera indispensável ter-se obtido num determinado país para que a origem da produção se fixe nesse país. Qualquer um destes critérios pode ser alterado por excepções que o tornam mais restritivo ou por modificações que o relaxam. Os três critérios podem ainda ser utilizados conjuntamente ${ }^{4}$.

${ }^{3}$ O princípio geral largamente aceite no direito do comércio internacional é o de imputar a origem à economia onde se deu uma transformação suficiente (sufficient working or processing), em acordos preferenciais, v.g. da UE, ou a última transformação substancial (last substantial process), em contextos não preferenciais. Cfr. CunHA, 1997: 99-100 e Hirsch, 2002: 177.

${ }^{4}$ Cfr. Cunha (1997: 100) e Cadot et al. (2008: 9 ss.). Para os casos NAFTA e PANEURO ver CADOT et al., op. cit., p. 12. 
O primeiro dos métodos tem a vantagem de fornecer indicações claras aos produtores externos quanto às operações de que terão que ser responsáveis para "adquirirem" a origem, sendo, no entanto, muito complicado para definir a origem de um vasto conjunto de produtos. O critério "técnico-produtivo" não se basta com um único requisito técnico, a ser aplicado a todos os produtos.

O método da mudança de posição pautal é de aplicação fácil mas tem o inconveniente de depender da nomenclatura harmonizada utilizada por todos os países da Organização Mundial das Alfandegas. A importância das categorias do Sistema Harmonizado - qualquer que seja o seu nível de agregação - varia entre sectores e, por conseguinte, variará também a natureza restritiva de uma mudança de posição pautal, a um mesmo nível de agregação, por ex. quatro dígitos. Assim, uma mudança de posição pautal fixada uniformemente para todos os sectores, no mesmo nível de agregação, gera forçosamente pedidos de relaxamento ou de reforço, através da introdução de excepções, critérios técnicos, etc. ${ }^{5}$. Ir pelo outro caminho, ou seja, admitir que uma mudança de posição pautal tanto pode ser exigida ao nível do capítulo (2 dígitos, o nível mais agregado) no âmbito do qual a transformação exigida é, em princípio, drástica, como ao nível de uma sub-posição (6 algarismos, o nível mais fino), no qual ela é supostamente bem menor, levanta também dificuldades e permite que se suscite a possibilidade da manipulação das regras de origem.

O método do conteúdo local não tem os inconvenientes dos métodos anteriores. Porque se baseia numa escala uniforme de unidades susceptíveis de medida (critérios de percentagem que permitem a medida e comparação), tem a grande vantagem de transmitir a extensão da protecção garantida pelas regras de origem. Por este motivo defende-se mesmo a con-

5 Cfr. Cadot et al., 2008: 35. 
versão dos outros dois métodos neste, admitindo-se até que esta conversão é o equivalente do processo de tarificação previsto no acordo sobre a agricultura do Uruguay Round ${ }^{6}$. Mas o "conteúdo local" apresenta outras dificuldades, a primeira das quais tem a ver com o facto de poder depender de uma avaliação do valor acrescentado. Como avaliar então o valor acrescentado (face aos custos de produção?, face ao preço de saída da fábrica?). Adoptar-se-ia um critério único de conteúdo local? Por outro lado, os países em vias de desenvolvimento (PVD), particularmente os países "mais atrasados" (PMA), sofreriam inconvenientes agravados, já que com maior probabilidade poderão estar a contribuir para uma fase intensiva em mão-de-obra não qualificada responsável por uma modesta fracção no valor dos produtos (daí a sua oposição a esta possibilidade na negociação dos acordos de parceria económica com a União Europeia ${ }^{7}$ ). Por seu turno, os países com custos de trabalho mais elevados estão em melhor posição para cumprir o "teste" do valor acrescentado. O mesmo resultado desigual obtém-se com preços diferentes dos inputs nas diferentes economias. Ou seja, a aplicação das mesmas local content rates tende a discriminar negativamente PVD, com vantagens comparativas assentes em trabalho e em materiais baratos ${ }^{8}$.

${ }^{6}$ Cfr. Hirsch, 2002: 185.

7 Cfr. Cadot et al., 2008: 36.

8 Cfr: Hirsch, 2002: 187-188. As regras de origem serão então “assimétricas", porque afectam de forma desigual os países que integram um EIR com estruturas produtivas e níveis de desenvolvimento económico distintos; daí a defesa de uma tratamento especialmente mais favorável para os PVD, em especial PMA. Na maioria dos acordos preferenciais (e regulamentações não preferenciais) os valores acrescentados oscilam entre os 35 e os 62,5\%. Hirsch propõe a redução destas taxas para combater a falta de "assimetria". 
5. As mais importantes regras de regime são as do cúmulo de origens. Se aceitarmos casos de origem cumulativa ou o cúmulo de origens, contamos, como se tivessem ocorrido num único país (em princípio o país exportador), contribuições para a produção da mercadoria levadas a cabo em vários países. A previsão do cúmulo de origens apresenta fortes vantagens para os produtores dos países exportadores beneficiados com tratamento preferencial: ao abrigo do regime da origem cumulativa, poderão utilizar inputs de outro ou outros países sem correrem o risco de perder o tratamento da preferência. O cúmulo de origens tem por conseguinte a capacidade de encorajar o comércio entre bens intermediários em espaços económicos alargados. E, como pode revelar-se bilateral, multilateral, diagonal ou integral, poderá fazê-lo em medidas distintas.

No âmbito do cúmulo integral, operações de fabrico levadas a cabo nos países beneficiários das preferências e no país ou EIR concedente serão consideradas da responsabilidade do país exportador ${ }^{9}$. No caso do cúmulo diagonal (ou regional), consideram-se cadeias de produção em que participem vários beneficiários, dentro de certos agrupamentos regionais, mas não o país ou EIR concedente ${ }^{10}$. Existe cúmulo multilateral quando, como resultado de um conjunto de acordos bilaterais celebrados entre o país ou EIR concedente e os países beneficiários, cada parte contratante pode utilizar, em certas

9 Era o caso da Convenção de Lomé. Nesta matéria, uma alteração foi introduzida pelo acordo de revisão da $4^{\text {a }}$ Convenção de Lomé. Abriu-se a possibilidade de se efectuar um cúmulo de origens entre Estados ACP e PVD vizinhos, para alguns produtos e países (cfr. CunHA, 1997: 101, nota 157). Um caso de extended cumulation, ao permitir a utilização de inputs de países não signatários do AIR, exactamente o método que, de acordo com EsTEVADEORDAl et al., 2009: 266, poderia revelar-se mecanismo eficaz para lidar com o problema do spaghetti bowl. Sobre esta prestação v. CunHa, 2007.

${ }^{10}$ No âmbito da Comunidade Europeia, esteve previsto para a ASEAN, o Grupo Andino e o Mercado Comum da América Central. 
condições e em maior ou menor grau, inputs com origem em outros países, partes contratantes nesse feixe de acordos bilaterais (ou ainda outras). Por conseguinte, este tipo de cúmulo resultará de uma combinação do cúmulo diagonal com o cúmulo bilatera ${ }^{11}$. Aceita-se o cúmulo bilateral quando se consideram as operações de fabrico levadas a cabo no país ou EIR concedente da preferência como sendo da responsabilidade do país exportador ${ }^{12}$.

Podemos apontar duas razões que justificam a existência dos vários tipos de cúmulos de origens. Em tese geral, aceita-se que existem países "terceiros" integrados economicamente, com interpenetração de muitos dos seus processos produtivos. Todavia, no caso do cúmulo bilateral e em particular neste, subverte-se claramente o conceito de transformação suficiente em prejuízo dos países recipientes de preferências, já que estes passam a utilizar inputs de esta ou daquela origem de acordo com o destino da exportação do bem acabado ou semi-acabado. Se, para mais, as regras de origem se revelarem restritivas, os prejuízos acentuam-se.

6. Avancemos na questão de saber se estas regras são instrumento de política comercial. As regras de origem poderão assumir a função de instrumento de política comercial se não se revelarem neutras, isto é, se comprovadamente forem responsáveis por encorajar ou dificultar a afirmação de deter-

11 O cúmulo multilateral esteve previsto nos acordos europeus de associação celebrados com os PECO. Assim, por exemplo, a Hungria poderia contar com um sistema de cumulação que permitia a utilização de matérias originárias de qualquer um dos países $\mathrm{PECO}$ e da própria Comunidade Europeia (e ainda da Islândia, da Noruega e da Suíça).Também os produtores comunitários poderiam contar com as vantagens do cúmulo multilateral, quando exportavam para esses países.

12 Estava previsto nos acordos "mediterrânicos" celebrados na década de 70 pela Comunidade Europeia. 
minados fluxos de comércio (ou a tomada de certas decisões de investimento). Servirão nomeadamente para a aplicação de medidas de política comercial restritivas (v.g. contingentes quantitativos discriminativos) ou para uma tentativa de circunscrição dos benefícios da liberalização intra-regional das trocas às economias participantes em EIR. Se estes envolverem preferências entre países desenvolvidos e PVD, descortinam-se desde já três vantagens: a) evitar que os países beneficiários das preferências sejam meros entrepostos comerciais. Na verdade, as pautas alfandegárias dos países desenvolvidos são em regra mais baixas do que as dos PVD (caso UE-ACP). Portanto, na perspectiva desses países, o risco de deflexão de comércio (v. infra) é baixo e não será esta a motivação primordial para as regras de origem preferenciais (v. também nota 25); b) encorajar nos PVD a instalação de processos produtivos com integração vertical, de forma a aumentar substancialmente a cadeia de valor. Nesta perspectiva, as regras de origem podem ser vistas como instrumentos atípicos de protecção de indústrias nascentes; c) institucionalizar o desvio de comércio (a deslocação de fontes de produção a custos mais baixos, do resto do mundo, para fontes de produção a custos mais elevados, localizadas no interior do EIR). Literatura recente prova que os AIR mais susceptíveis de gerar desvio de comércio os piores de um ponto de vista de bem estar global - são, et pour cause, os mais aceitáveis politicamente. Assim, regras de origem que "organizem" o desvio de comércio são contributo para tornar estes acordos mais aceitáveis politicamente ${ }^{13}$. Mas também podemos lobrigar inconvenientes. Pense-se, por exemplo, na aplicação de regras de origem que resulte na eliminação de facto de preferências para certos produtos industriais originários de PVD. Tê-las-emos como instrumento de neutralização dos benefícios da liberalização comercial discri-

13 Cfr. Сadot et al., 2008: 14. 
minativa. Podemos ainda assistir a outras incidências "assimétricas" (v. supra nota 8).

7. A importância do comércio de inputs e o reconhecimento do relevo da internacionalização dos processos produtivos está patente nos tópicos que abordaremos de seguida, desde logo em uma análise da estrutura da protecção em economias desenvolvidas. Esta traduz habitualmente uma liberalização no comércio de produtos industriais (em relação aos quais os PVD não tinham tradicionalmente capacidade produtiva) e uma protecção crescente nos sectores da agricultura e da produção de produtos industriais vulgarmente trabalho-intensivos, como sejam os têxteis e o vestuário (sectores em que há décadas PVD têm vantagem comparativa). MurRAY (1977: 8) salienta mesmo estes efeitos, considerando que a típica estrutura alfandegária a enfrentar pelos PVD se pode representar por uma pirâmide. Temos franquias alfandegárias ou baixos impostos para as matérias-primas necessárias à indústria mas assistimos a uma gradual «escalada» alfandegária para os produtos (de base) já processados e para os produtos semi-acabados e acabados. Esta disposição vertical dos impostos constitui uma efectiva barreira à industrialização, já que desencoraja mesmo o simples processamento de matérias-primas.

No âmbito das preferências dadas aos PVD (v.g. SPG) utilizam-se regras de origem tradicionais associadas ao critério da mudança de posição pautal ou da regra da percentagem. Estas regras pouco fazem para evitar os efeitos perniciosos da escalada na tributação alfandegária. Para isto basta que as preferências não se estendam a bens com um maior grau de processamento ou que, não sendo este o caso, os últimos estádios de produção de um bem se desenvolvam em países que não beneficiem da preferência ${ }^{14}$.

14 Cfr. Lloyd 2002: 172-173. 
Com este apontamento sobre o fenómeno da "escalada" alfandengária, iniciamo-nos na percepção de que os países formulam diferentes conjuntos de regras de origem para objectivos distintos e frequentemente especificam-nas de forma a criar preferências à la carte para inputs "preferidos"15.

Temos depois um segundo conjunto de problemas, desta vez relacionado com o tratamento de "conteúdo local" de bens importados. O art.VII do GATT define valor alfandegário em termos que não permitem excluir desse valor o conteúdo doméstico incorporado no bem importado. Supõe-se por conseguinte que toda a produção "nacional" é levada a cabo no interior das fronteiras "nacionais", nessa e em outras economias. Não obstante, legislação comercial europeia e outras (v.g. norte-americana, australiana) prevê o chamado regime de aperfeiçoamento passivo. Quando uma mercadoria é em parte produção da UE e em parte produção externa, o regime de aperfeiçoamento passivo permite que, quando essa mercadoria, fabricada na UE, é importada, após a transferência e a realização de parte das operações do seu fabrico no exterior, ela beneficie de uma taxa de tributação alfandegária tanto mais reduzida quanto maior tiver sido o valor previamente acrescentado na UE ao referido produto. $\mathrm{Na}$ verdade, o importador pagará, quando introduzir a mercadoria de novo

15 Ou para produtores "preferidos”. Para este último caso pense-se desde já no exemplo dado por CADOt et al. (2008: 9). Suponhamos que o Norte se confronta com um declínio da sua indústria têxtil-vestuário mas tem uma desvantagem comparativa relativamente menos grave no segmento dos bens intermediários intensivo em capital, por exemplo tecidos. O seu parceiro do Sul, também ele em desvantagem comparativa face aos produtores eficientes da Ásia, é relativamente menos ineficaz na montagem, isto é, na confecção. Um AIR entre Norte (UE) e Sul (África subsaariana) permitirá criar uma espécie de mini-mundo no qual terá lugar um comércio do tipo Heckscher-Ohlin. O Norte exportará bens semi-acabados para o Sul e o Sul acabá-los-á e exportá-los-á para o Norte. Este processo produtivo é globalmente ineficaz mas, na ausência do AIR, toda esta produção se deslocalizaria para a Ásia. 
em território da UE, um imposto igual à diferença entre o montante de imposto devido pela importação do produto transformado e o montante de imposto devido pela importação do produto de base ou do bem semi-acabado previamente exportado para transformação ${ }^{16}$. Muito deste "aperfeiçoamento" resulta de IDE realizado por empresas europeias que deslocalizam parte da produção para beneficiarem de menores custos de produção ou de montagem.

Por último, cumpre-nos recordar o conceito de protecção efectiva (de protecção ao valor acrescentado). Numa economia desenvolvida, com um complexo de actividades produtivas, cada uma delas utiliza como inputs produtos de outras actividades e produz output que, na totalidade ou em parte, pode servir de input em outras actividades. Logo, os impostos alfandegários que compõem uma dada estrutura alfandegária influenciam a localização das actividades nesse país (ou espaço económico) e também nos outros países ou espaços económicos que exportam para o primeiro, de duas formas distintas: por um lado, os impostos alfandegários que recaem sobre o output "subsidiam" a localização dessa actividade dentro desse país; pelo outro, os impostos alfandegários que recaem sobre os inputs "tributam" e nessa medida oneram a localização dessa actividade dentro do país. Para determinar a influência da estrutura alfandegária na localização das actividades teremos que, especificamente, determinar não só os "subsídios" mas também os "impostos" que recaem sobre o valor acrescentado nessas mesmas actividades, contidos no todo da estrutura alfandegária ${ }^{17}$. Ora, no âmbito da aquisição da origem para efeitos de tratamento pautal preferencial em mercado de exportação, também as regras de origem podem ser vistas como um imposto e um subsídio, um imposto sobre inputs importados e um subsídio aos inputs domésticos ${ }^{18}$. Assim se entende que, quando se pre-

\footnotetext{
16 Cfr. Cunha, 1997: 90-91.

17 Para mais desenvolvimentos, cfr. CunHa, 1995: 92 ss.

18 Cfr. Rosellón, 2000: 399.
} 
para a negociação de um acordo de comércio livre, se gere um conflito entre os produtores nacionais ou regionais de inputs de certo produto final e os produtores do produto final. Os primeiros quererão regras restritivas para a aquisição da origem para o produto final. Os segundos defenderão regras menos restritivas para poderem ter acesso a inputs de diversas fontes ${ }^{19}$. Em circunstâncias destas, as regras de origem poderão produzir efeitos semelhantes aos de um subsídio à exportação. Suponhamos um AIR entre dois parceiros, um desenvolvido e outro em vias de desenvolvimento. $O$ país desenvolvido tem vantagem relativa, face ao $\mathrm{PVD}$, na produção de bens intermediários, e o PVD tem-na no que respeita à montagem ou confecção do produto. As regras de origem "obrigam" o PVD a adquirir os bens intermediários ao país desenvolvido. Neste, o preço desses bens intermediários será igual ao preço mundial acrescido do imposto da "nação-mais-favorecida" (na exportação para o PVD, poderá até ser superior a esse valor) no país desenvolvido. Como resultado da preferência alfandegária geram-se rendas no país desenvolvido, compensadas pela perda de receita alfandegária aí verificada. Daí a equivalência a um subsídio (encapotado) à exportação.

8. Passemos às diversas justificações para as regras de origem preferenciais. Em primeiro lugar, o estabelecimento de regras de origem será fundamental se pensarmos numa ZCL, porque aí só as mercadorias que devam ser consideradas como originárias dos Estados participantes (e não as importações que cada um deles efectua do resto do mundo) poderão beneficiar da livre circulação que a formação da zona implica. Estas regras procuram então evitar deflexão do comércio internacional ou desvio de tráfego comercial. $\mathrm{Na}$ ausência de regras de origem, criar-se-ia uma oportunidade de arbitragem, fazendo transitar as importações do conjunto da zona (aquelas

19 Cfr. Rosellón, 2001: 3. 
que têm como origem o resto do mundo) pelo país ou países do EIR com impostos mais baixos.

Com este desiderato legítimo, estas regras tornam-se no entanto susceptíveis de manipulação, para fins meramente proteccionistas. Empresas estrangeiras podem ser convidadas a investir no território do EIR - e a aí produzirem inputs que poderiam produzir eficientemente algures e depois exportar para o dito espaço - de forma a mais facilmente observarem as regras de origem ${ }^{20}$.Assim, os efeitos das regras de origem far-se-ão sentir em particular na importação de produtos intermediários de países terceiros ao EIR. Regras severas não serão mais do que barreiras ao comércio desses produtos, na medida em que se desencoraja a sua incorporação na produção doméstica dos Estados-membros do espaço com destino intra-regional. $\mathrm{Na}$ verdade, estas regras - da mesma forma que a redução ou eliminação discriminativa dos impostos alfandegários - podem produzir efeitos de desvio de comércio ${ }^{21} 22$. Poderemos iden-

${ }^{20}$ Cfr., por exemplo, Han (1992: 24; 34-35). Neste estudo, que respeita a fluxos de investimento directo externo da Coreia do Sul para a Comunidade Europeia, no ramo da electrónica, identifica-se, entre outras motivações secundárias para esse investimento, o cumprimento das regras de origem. Por seu turno, Bhalla e Bhalla (1997: 198) referem que algumas multinacionais dos Estados Unidos adoptaram comportamento similar na NAFTA.

21 Lawrence (1996: 50) e Krueger (1999: 929) recordam um exemplo da NAFTA. A livre-circulação intra-regional de certos produtos de vestuário obriga a uma produção realizada em 100\% nas economias deste EIR (inputs, fabrico, etc.). Para automóveis, bastam 50\% de valor acrescentado na América do Norte. Ainda a propósito das regras de origem aplicadas no âmbito da NAFTA, registamos a observação de HUDEC e Southwick (1999: 56): "One need only look at the NAFTA rules of origin for textiles and apparel, color televisions and automobiles to see mastery in engineering rules of origin.”.

22 Esta matéria, que emerge com a constituição de ZCL, ganha especial sensibilidade no âmbito da análise dos efeitos económicos dos sistemas de acordos de comércio livre de tipo "radial". Este é assunto que 
tificar melhor os efeitos de desvio de comércio das regras de origem, no que se refere à importação de bens intermediários, se de novo aceitarmos que estas actuam como um imposto sobre inputs com origem extra-regional - havendo perda da garantia do livre-comércio intra-regional para os bens produzidos na ZCL que incorporem os ditos inputs.

Imaginemos que um produtor localizado numa das economias da ZCL, estando obrigado a incorporar no bem uma determinada percentagem mínima de produção intra-regional para adquirir a origem (determinada, aliás, arbitrariamente), o está a efectuar "na margem" (sem qualquer espaço de manobra). Nestas circunstâncias, havendo o risco de se perder a origem e por conseguinte a garantia da livre circulação intra-regional do bem, pode o produtor, preventivamente, substituir alguns inputs importados do resto do mundo por inputs produzidos na ZCL. Admitindo que os fornecedores destes inputs na ZCL são menos eficientes do que os do resto do mundo, a mudança gera desvio de comércio (sobre bens intermediários). Em matéria (da distribuição) dos efeitos deste desvio de comércio, ficam a ganhar os produtores regionais de inputs, a produção local de maior valor acrescentado (que não perde a origem - isto desde que o ganho que obtém por esse facto seja superior ao acréscimo de custos suportado) e os consumidores das economias da ZCL que importam o produto (acabado) de um dos seus parceiros regionais (a um preço inferior ao do resto do mundo, com imposto alfandegário). Sofre-se uma dupla perda de receitas alfandegárias, tanto daquelas antes cobradas com a importação de inputs do resto do mundo (no pais onde se localiza a produção) como de outras, antes cobradas nos países do EIR destinatários do produto acabado, se estes estiverem a substituir produção do

tratámos desenvolvidamente em CunHA, 2007, remetendo-se agora para essa referência bibliográfica. 
resto do mundo por uma importação insusceptível de tributação nessas economias ${ }^{23}$

9. É certo que o art. $24^{\circ}$ do GATT, permitindo a criação de EIR (ZCL ou união aduaneira), estipula genericamente que o ensejo não deve ser aproveitado para levar a cabo um reforço das barreiras comerciais face ao exterior (os países terceiros ao AIR). Esta aparente restrição a abusos na especificações das regras de origem em ZCL, não se tem, no entanto, revelado efectiva, provavelmente por falta de suficiente densificação. De tal forma assim é que, nesta matéria, os autores avançam, amiúde, propostas. SERRA et al. (1997: 14; 46) propõem que se obriguem liminarmente os Estados participantes numa ZCL a não agravarem a natureza restritiva das regras de origem. No mesmo sentido, Puche (2000: 127-128) sugere que, na medida do possível, as regras de origem não se tornem mais restritivas, não obrigando, para efeitos de aquisição de origem (agora preferencial), à incorporação de um maior conteúdo regional para as exportações intra-regionais do que antes (não sendo possível, o autor propõe compensações).

O inconveniente destas soluções, apontado por ScHIFF e Winters (2003: 252), está em que, pela complexidade das regras de origem - e pelas alterações que nelas são introduzidas para fazer face, por exemplo, à evolução tecnológica -, é difícil comprovar o cumprimento da dita obrigação. Para estes autores, a solução estaria em obrigar os países a aderir a regras de origem definidas internacionalmente - ou então as regras de origem para relações preferenciais teriam que ser iguais às regras para relações não preferenciais (a nosso ver, esta última proposta peca por ignorar os perigos de deflexão de comércio em ZCL, a que poderiam não ser imunes

23 Cfr. Pomfret (1997: 235). 
produtos intermediários, se as regras de origem se revelassem permissivas a $\left.\operatorname{tal}^{24}\right)$.

LAWRenCe (1996:51) propõe uma única regra de origem em ZCL para todos os produtos, em termos v.g. de percentagem de valor acrescentado internamente ou de definição do que se entende por transformação substancial. Podendo haver alguns inconvenientes, já que a dita regra se adequaria melhor a uns casos do que a outros, retirava-se à mesma grande parte do potencial para uma utilização com intuitos proteccionistas. No mesmo sentido, afirmam-se PARK (2002: 281), quando sugere uma única definição de regras de origem, aplicável a todos os produtos, e KRUEGER (1999: 929). Esta autora lembra que o facto de as regras de origem poderem ser fixadas produto a produto (itemised) torna-as susceptíveis a servir como instrumento de discriminação contra produtores de países terceiros. Sugere também um critério singular, expresso num único valor acrescentado.

Uma solução intermédia é apontada por NaGARAJAN (1998: 4). O autor recorda que, com a proliferação de ZCL nos anos recentes, levanta-se um problema sério a propósito das regras de origem preferenciais. Defende ainda que movimentos recentes da UE e dos seus parceiros nos acordos europeus para estabelecer um cúmulo diagonal de origens oferecem um modelo para outros países seguirem. Não obstante, também para NaGARAJAN o objectivo último deverá ser o da adopção de um conjunto único de regras de origem para todos os acordos ou de um standard internacional que deve ser observado pelas diferentes regras de origem.

10. Sofrem-se ainda outros inconvenientes, em ZCL, por força da criação de regras de origem. Em primeiro lugar,

24 Em sentido convergente, embora a outro propósito, Nagarajan (1998: 14). 
não é possível esquecer os custos de administração e aplicação das ditas regras, até por força da sua complexidade. Ora, sendo certo que também uma união aduaneira obriga à aplicação de regras, acontece ser apenas no âmbito da ZCL que as regras de origem são factor de determinação dos fluxos de comércio que se estabeleçam entre os membros da zona - e isto porque, como já sabemos, só os produtos originários de cada um dos ditos países poderão circular livremente entre eles. Havendo união aduaneira, há livre circulação de praticamente todos os produtos existentes em cada um dos membros, desde que os mesmos tenham sido produzidos nesses países ou hajam sido regularmente importados (e também desde que, evidentemente, sejam susceptíveis de troca internacional).

Convirá igualmente alertar para o facto de a acção dos lobbies poder naturalmente abarcar a própria definição das regras de origem, no sentido de facilitar ou de dificultar a incorporação de elementos externos em produção dita "nacional". Pensando de novo no caso da ZCL, teríamos então que considerar a capacidade de os lobbies supra referidos poderem interferir não só nos níveis de defesa comercial de cada país face à produção estranha à ZCL como também no volume e na composição do (livre) comércio de cada um deles com os restantes - na medida em que esse comércio se faça com produtos apenas parcialmente produzidos nos países em causa.

11. Podem por conseguinte as regras de origem, em ZCL, para além de levantarem barreiras comerciais entre países membros e não membros, levantar barreiras entre os países membros do EIR, inibindo o próprio comércio intra-regional. É este o caso da trade regression, dando-se uma reafectação ineficiente de produção entre membros da zona. Acontece quando regras de origem são aplicadas a bens intermediários comercializados directamente entre países membros da 
ZCL e ocorre simultaneamente com o desvio de comércio que afecta o país não membro. Embora a trade regression não esteja presente no comércio de produtos finais entre os membros da ZCL, ela afecta o comércio vertical em bens intermediários $^{25}$. Por conseguinte, regras de origem restritivas podem encorajar investimento, inclusive IDE, ineficiente e a relocalização de estádios da produção entre os membros da ZCL. Hipótese semelhante, mas envolvendo especificamente países ou EIR desenvolvidos e PVD, é chamada à colação por Flatters e Kik (2003: 15). Imagine-se que um pequeno produtor africano de têxtil é obrigado, para entrar no grande mercado europeu, a cumprir regras de origem que o obrigam a adquirir localmente inputs. Já os produtores europeus podem comprar os mesmos inputs aos preços mundiais. Mesmo que não adquiram origem para exportação preferencial, têm o grande mercado europeu para venderem; não têm, para esse efeito, que atravessar fronteiras. Assim, regras de origem restritivas podem limitar os efeitos da liberalização intra-regional do comércio em desfavor da parte mais fraca.

${ }^{25}$ Cfr. Rodriguez, 2001: 201 e 219. Ainda a este propósito, podemos registar um caso concreto apontado por PANAGARIYA (1999: 17), que, em concordância com o que já referimos no texto, prova que as regras de origem podem revelar-se (mais) um instrumento à disposição dos lobbies para acentuar o desvio de comércio ou impedir a criação de comércio. O autor lembra, mais uma vez no âmbito da NAFTA, que as rigorosas regras de origem exigidas pelos Estados Unidos não se destinaram primordialmente a impedir deflexão de comércio internacional (admitindo-se que esses produtos poderiam ser importados do resto do mundo, nos Estados Unidos, servindo o México como “entreposto”), já que os impostos dos Estados Unidos eram geralmente inferiores aos impostos mexicanos, mas antes a dificultar que produtos mexicanos, com inputs importados de Estados terceiros, obtivessem a origem da ZCL e assim circulassem livremente em espaço regional (podendo, portanto, entrar livremente nos Estados Unidos). 
12. Actualmente, os membros da OMC são livres na definição das suas regras de origem, preferenciais e não preferenciais. Não obstante, os problemas são muitos: as regras podem revelar-se arbitrárias, na imputação da origem a esta ou aquela economia, e podem levar a significativas alterações na tributação alfandegária com pequenas mudanças em fornecimentos de inputs ou nos preços desses inputs (ou ainda por força de variações cambiais). Para mais, a proliferação de AIR e o temido aumento das barreiras comerciais restritivas e selectivas permite augurar um aumento da importância das regras de origem. Assim, uma quase absoluta liberdade para tratar estas regras como instrumento de política comercial não é de todo desejável. Se nada se fizer, a mesma combinação de forças que permitiu a globalização terá aumentado a capacidade de os países limitarem o acesso aos seus mercados a produtos e a fontes produtivas beneficiários de tratamento pautal preferencial $^{26}$.

13. A complexidade das regras de origem e o spaghetti bowl dos AIR tornam estas regras, distintas para cada acordo, um quebra-cabeças para os exportadores. A UE começou a reformar o seu sistema adoptando em 1997 uma "lista única" que harmonizou as "regras de lista" de todos os acordos preferenciais, de forma a facilitar o cúmulo de origens, em particular o cúmulo diagonal. Esta "lista única" representou à época um grande progresso no sentido da simplificação e da harmonização de regras de lista entre acordos preferenciais. Ainda assim, dados trabalhados por CAdot e Melo (2007) sugerem que a natureza restritiva das regras de origem de lista, no âmbito da NAFTA mas também da PANEURO, parece mais acentuada nas linhas caracterizadas por picos de tributação alfandegária, sugerindo que as mesmas forças políticas

${ }^{26}$ Neste sentido, Rodriguez, 2001: 201. 
geram impostos elevados e regras de origem restritivas. Por este motivo se saúda que, em 2005, a UE se tenha proposto ir mais longe na simplificação através da adopção de um instrumento único (no lugar da lista única). Este consistiria numa regra de conteúdo local (ou numa limitação de conteúdo externo, o que seria equivalente), em substituição do conjunto de regras de lista diversificadas utilizados actualmente, e com um valor ainda por definir ${ }^{27}$. A efectiva substituição de um sistema de lista única por um de instrumento único tem as vantagens da simplificação e da transparência, as mesmas que explicam a tarificação das barreiras não pautais, a que já aludimos, e não impede ajustamentos específicos para PMA (taxa mais baixa; critério alternativo de mudança de posição pautal). E estas vantagens repercutir-se-iam multilateralmente, porque a UE marcaria a agenda multilateral com um sistema claro e transparente. Ora a harmonização das regras de origem é importante, nomeadamente com a actual proliferação dos AIR, e mais importante é que se faça independentemente destes, porque regras complicadas e opacas são sempre barreira às trocas comerciais multilaterais ${ }^{28}$. Deve ainda pensar-se numa simplificação das regras de cumulação de origens, quiçá gene-

27 Houve entretanto recuos, mantendo-se nos acordos de parceria económica regras de origem que remontam ao Acordo de Cotonou (cfr. Naumann, 2008). Por sua vez, o SPG, beneficiou de novas regras de origem, com aplicação a partir de 1.1.13, adoptadas no desenvolvimento dos princípios estabelecidos pela Comissão em 2005 e por conseguinte com alguma simplificação.

28 Cfr. CADOT et al., 2008: 44-45. A este propósito lembramos IzAM (2004: 445), quando define aqueles que considera serem os princípios mais importantes das regras de origem: simplicidade: devem ser claras e transparentes para tornar mínima a possibilidade de se aplicarem de forma discriminativa ou fraudulenta; previsibilidade: devem ser estáveis para que o sector produtivo possa actuar estrategicamente, ou seja, no longo prazo; devem ainda poder administrar-se com eficiência e essa administração deve ser susceptível de controlo. 
ralizando o cúmulo integral ${ }^{29}$ e talvez avançando mesmo para além dele (recorde-se a nota 9). Divergências entre conjuntos de regras de origem aumentam consideravelmente os custos de transacção a suportar por países/empresas que lidem simultaneamente com mais de um AIR, nomeadamente se entre estes não houver cúmulo de origens, com as consequentes facilidades na utilização de inputs de origens diversificadas. Daí o interesse nos cúmulos de origens entre os membros desses acordos. Por sua vez, um acordo multilateral sobre regras de origem preferenciais contrariaria a tendência para a formação de amplas "áreas de cumulação" de origens com exclusão de inputs do resto do mundo. Ao invés, promover-se-iam cúmulos de origens alargados, entre diversos AIR.

\section{BIBLIOGRAFIA}

Bhalla, A. S.; Bhalla, P., 1997 - Regional Blocs - Building Blocks or Stumbling Blocks, Londres, MacMillan.

Cadot, Olivier; Melo, Jaime de, 2007 - "Why OECD Countries should Reform Rules of Origin", World Bank Research Observer.

Cadot, Olivier; Djiofack, Calvin; Melo, Jaime de, 2008 - "Préferences commerciales et règles d'origine: perspectives des Accords de Partenariat Economique pour l'Afrique de l'Ouest et centrale", Revue d'Economie du Devéloppment, n. ${ }^{\circ}$ 3, pp. 5-48.

Cunha, Luís Pedro, 1995 - O Sistema Comunitário de Preferências Generalizadas - Efeitos e Limites, Coimbra, separata do Boletim de Ciências Económicas da Faculdade de Direito da Universidade de Coimbra.

—, 1997 - Lições de Relaçooes Económicas Externas, Coimbra, Almedina.

—, 2007 - "A proliferação de acordos de integração regional", Boletim de Ciências Económicas, Faculdade de Direito da Universidade de Coimbra, vol. 50, pp. 353-393.

Estevadeordal, Antoni; Harris, Jeremy; Suominen, Kati, 2009 - "Harmonizing preferential rules of origin regimes around the world", in

${ }^{29}$ Cfr. Cadot et al., ibidem. 
Richard Baldwin e Patrick Low (eds.), Multilateralizing Regionalism - Challenges for the Global Trading System, pp. 262-363.

Flatters, F.; KIK, R., 2003 - Rules of Origin as Tools of Development? Some Lessons from $S A D C$.

Han, Sun-Taik, 1992 - “European Integration: The Impact on Asian Industrialising Economies", Development Centre Documents, Paris, OECD.

Hirsch, Moshe, 2002 - "International Trade Law, Political Economy and Rules of Origin - A Plea for a Reform of the WTO Regime on Rules of Origin", Journal of World Trade, volume 36, n. ${ }^{\circ}$ 2, pp. 171-188.

Hudec, Robert E.; Southwick, James D., 1999 - "Regionalism and WTO Rules: Problems in the Fine Art of Discriminating Fairly", in Miguel Rodríguez Mendoza et al. (eds.), Trade Rules in the Making - Challenges in Regional and Multilateral Negotiations, Washington, Organization of American States, pp. 47-80.

IzAm, Miguel, 2004 - "Normas de origen y facilitación del comercio en America Latina”, Comercio Exterior, vol. 24, n. ${ }^{\circ}$ 5, pp. 444-455.

Krueger, Anne O., 1999 - “The Developing Countries and the Next Round of Multilateral Trade Negotiations", The World Economy, vol. 22, no 7, pp. 909-932.

Lawrence, Robert Z., 1996 - "Regionalism and the WTO: Should the Rules Be Changed?”, in Jeffrey J. Schott (ed.), The World Trading System - Challenges Ahead, Washington, Institute for International Economics, pp. 41-56.

LlOYd, P. J., 2002 - "Country of origin in the global economy", World Trade Review, vol. 1, n. ${ }^{\circ}$ 2, pp. 171-185.

Murray, Tracy, 1977 - Trade Preferences for Developing Countries, MacMillan.

Nagarajan, Nigel, 1998 - "Regionalism and the WTO: New Rules for the Game?", Economic Papers 128, European Commission - Directorate-General for Economic and Financial Affairs.

Naumann, Eckart, 2008 - "Rules of Origin and Economic Partnership Agreements: what has been agreed? What does it mean? What next?, Tralac.

Panagariya, Arvind, 1999 - Regionalism in Trade policy - Essays on Preferential Trade, Singapura, World Scientific.

PArk, Sung-Hoon, 2002 - "Regionalism, Open Regionalism and Article XXIV GATT: Conflicts and Harmony”, in Francis Snyder (ed.), Regional and Global Regulation of International Trade, Oxford, Hart Publishing, pp. 263-283.

Pomfret, Richard, 1997 - The Economics of Regional Trading Arrangements, Oxford, Clarendon Press. 
Puche, Jaime Serra, 2000 - "Regionalism and the WTO”, WTO (ed.), From GATT to the WTO: The Multilateral Trading System in the New Millenium, Haia, Kluwer Law International / World Trade Organization, pp. 123-135.

Rodriguez, Peter L., 2001 - "Rules of Origin with Multistage Production", The World Economy, vol. 24, n. ${ }^{\circ} 2,201-220$.

Rosellón, Juan, 2000 - "The economics of rules of origin", The Journal of International Trade \& Economic Development, vol. 9, n. ${ }^{\circ} 4$, pp. 397-425 .

—, 2001 - "Reglas de origen y análises del bienestar", El Trimestre Económico, vol. 68, pp. 3-38.

Schiff, Maurice; Winters, L. Alan, 2003 - Regional Integration and Development, Washington, The World Bank.

Serra, Jaime et al., 1997 - Reflections on Regionalism - Report of the Study Group on International Trade, Washington, Carnegie Endowment for International Peace. 
Resumo: Neste texto começa-se por descrever as regras básicas do direito do comércio internacional sobre a definição das regras de origem, em contextos preferenciais e não preferenciais, e das origens cumulativas. Admite-se de seguida que essas definições, nomeadamente no âmbito da formação de zonas de comércio livre, podem manipular-se com fins proteccionistas. Esta possibilidade é estudada, destacando-se os efeitos de desvio de comércio sobre bens intermediários do resto do mundo e de trade regression que podem afectar o comércio intra-regional. A propósito da importância do comércio de inputs e do reconhecimento do relevo da internacionalização dos processos produtivos, referem-se o problema da escalada na tributação alfandegária, o regime do aperfeiçoamento passivo e o conceito de protecção efectiva. São ainda mencionadas propostas para uma futura abordagem multilateral das regras de origem e a evolução da UE nesta matéria.

Palavras-chave: Regras de origem, Cúmulo de origens, Origem cumulativa, Desvio de comércio, Trade regression, Comércio internacional.

Considerations on the significance of rules of origin in international trade

Abstract: This text begins by describing the basic rules of international trade law regarding the definition of rules of origin, both in preferential and non-preferential contexts, and the definition of cumulative origins. It is then assumed that these definitions, particularly in the context of the formation of free trade areas, can be manipulated with protectionist purposes. This possibility is studied with emphasis on the trade diversion effects on intermediate goods from the rest of the world and the effects of trade regression that may impair intra-regional trade. With regard to the present importance of international trade in inputs and the internationalization of production, we refer to the issue of tariff escalation, to the outward processing procedure and to the concept of effective protection. We lastly refer both to proposals for a multilateral approach to future rules of origin and to the evolution of the EU in this domain.

Keywords: Rules of origin, Cumulative origin, Trade diversion, Trade regression, International trade.

Luís Pedro Cunha

Faculdade de Direito da Universidade de Coimbra 